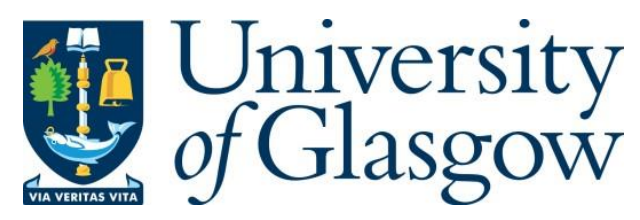

Vestrum, I., Rasmussen, E. and Carter, S. (2017) How nascent community enterprises build legitimacy in internal and external environments. Regional Studies, 51(11), pp. 1721-1734.

There may be differences between this version and the published version. You are advised to consult the publisher's version if you wish to cite from it.

http://eprints.gla.ac.uk/212037/

Deposited on: 4 May 2020

Enlighten - Research publications by members of the University of Glasgow http://eprints.gla.ac.uk 


\title{
How Nascent Community Enterprises Build Legitimacy in Internal and External \\ Environments
}

\section{Ingebjorg Kluken Vestrum,}

Bodø Graduate School Of Business, University Of Nordland

Einar Rasmussen,

Bodø Graduate School Of Business, University Of Nordland

Sara Carter,

Hunter Centre For Entrepreneurship, University of Strathclyde

\begin{abstract}
Community enterprises (CEs) have become a widely used mechanism in addressing problems associated with socio-economic decline in rural areas. Using a legitimacy perspective, we explore how emerging CEs are able to access resources needed to start and sustain their operations. Studying two music festivals that aim to improve the identity and economy of rural communities, we show that the legitimation process requires different legitimacy building strategies within different environments. Three key legitimation strategies emerge: conformance to the internal (rural community) environment; conformance to the external (cultural festival) environment; and changing the internal (rural community) environment. Legitimacy is built in an iterative process, where CEs leverage legitimacy developed in one environment to build legitimacy in a different stakeholder audience. Hence, new ventures can strategically benefit from differences in legitimacy judgements among different audiences.
\end{abstract}

Keywords: community enterprise; entrepreneurship process; legitimacy; music festivals; resource acquisition; rural communities. 


\section{INTRODUCTION}

Cultural activities such as music festivals may be a rich source of economic, social and cultural capital for their local communities (DELAMERE, 2001; GURSOY et al., 2004; TAYLOR, 2013). Local arts and cultural activities have been found to strengthen sense of place and community identity, and enhance civic participation, social interaction and the well-being of remote and rural residents (MAYES, 2010; ANDRES and CHAPAIN, 2013). While prior studies have debated the socio-economic value of local cultural activities (BOYLE, 1997), our study makes a novel attempt to uncover the entrepreneurial process by which new cultural activities in remote rural communities can be created and sustained. By taking a legitimacy perspective, we add to the literature about the origin of entrepreneurial activities in rural areas and the interdependencies between the local community and the external environment in entrepreneurial processes (MARKUSEN, 2010; KIBLER et al., 2014). Our study also provides a novel account of the understudied issue of multi-level dynamics among different stakeholders in the legitimizing process (BITEKTINE and HAACK, 2015; CASTELLÓ et al., 2015).

An important vehicle for introducing new cultural activities in rural areas is the creation of non-profit community enterprises (CEs). CEs seek to create social value for their community and typically attempt to stimulate social and cultural life, increase business development and strengthen community identity with the aim of building community resilience. These enterprises contribute to revitalizing communities which are experiencing economic stagnation or decline or are facing the challenges arising from depopulation (JOHANNISSON, 1990; JOHNSTONE and LIONAIS, 2004). The types of activities undertaken by CEs include sports or cultural events (HAUGH and PARDY, 1999), museums (BORCH et al., 2008), business networks 
(JOHANNISSON, 1990; JOHNSTONE and LIONAIS, 2004), health conversion foundations (HEINZE et al., 2016) and job creation organizations (LOTZ, 1989). While a plethora of CEs exist to address a range of societal and social welfare problems, relatively little research has investigated their organization creation process and the specific challenges and constraints that they face (MAIR and MARTÍ, 2006; PEREDO and MCLEAN, 2006; DASKALAKI et al., 2015).

Studies that have focused on the sustainability of remote rural communities have drawn attention both to the vital role played by social actors in realizing the potentialities of these places and the importance of entrepreneurial skills and resources in shaping rural change (ALSOS et al., 2011; BEAUDOIN et al., 2011). Entrepreneurs in rural areas may face an initial lack of resources and knowledge that needs to be offset through the integration of new external resources. However, one of the greatest challenges for entrepreneurs trying to launch new activities is that they lack the legitimacy needed to convince resource providers to back their ventures (KIBLER et al., 2014; ZIMMERMAN and ZEITZ, 2002; ÜBERBACHER, 2014). Hence, legitimacy is seen as a resource in its own right and also as a necessary precursor to the acquisition of other critical resources (ZIMMERMAN and ZEITZ, 2002; LOUNSBURY and GLYNN, 2001). While there is a growing understanding of the role of legitimacy as a crucial resource and the first step in mustering support for emerging commercial ventures (ÜBERBACHER, 2014; VAN WERVEN et al., 2015), legitimacy has not been addressed within the community entrepreneurship literature.

This paper explores how nascent CEs in the cultural sector build the legitimacy needed to introduce novel and radical ideas into rural communities. Legitimacy is highly situated in the local context and legitimating new practices among stakeholders in rural areas has been described 
as a key challenge involving a mix of competing rationales (KIBLER et al., 2014). We propose that gaining legitimacy is particularly relevant for emerging CEs. Community-based organizations are not driven by a profit motive, and their success is not measured in terms of the profit they generate (AUSTIN et al., 2006; HAUGH, 2007). To do this successfully, CEs need to legitimize their role and position as perceived by different stakeholders, and often need to convince resource providers to accept non-financial gains in exchange for resources. Moreover, CEs are dependent on the local community for access to a range of resources and need to create opportunities for engagement within the local community to reach their goals of meeting local community needs (HAUGH, 2007; PEREDO and CHRISMAN, 2006).

Understanding the process of gaining legitimacy is typically deduced retrospectively (ZIMMERMAN and ZEITZ, 2002), as it is difficult to gain access to the earliest phases of legitimacy building. We resolved this challenge by conducting a longitudinal case study of the start-up process of two music festivals that each aimed to revitalize remote rural communities in Norway. By investigating the venture formation process, from an early stage following idea conception until the venture has achieved its social goal, we show how CEs gradually gain legitimacy. Building on a legitimacy perspective, our study uses a novel theoretical framework that takes into account how nascent CEs can move beyond their current stocks of resources to launch new activities in rural communities. Moreover, we add to the understanding of legitimacy building by elucidating how CEs can leverage legitimacy developed in one environment to build legitimacy in a different environment with different stakeholders.

\section{THEORETICAL FOUNDATIONS}




\section{Community Entrepreneurship}

Traditional perspectives of entrepreneurship research have focused on commercial ventures aiming to create personal wealth and economic values for shareholders (HAUGH and PARDY, 1999). However, a growing research theme has been the development of social, community and non-profit enterprises (MAIR and MARTÍ, 2006; PIERRE et al., 2014). These enterprises are valued for their potential to create social wealth and their focus on the "economic, societal, health, and environmental aspects of human welfare" (ZAHRA et al., 2008 118). Community entrepreneurship, often viewed as a sub-set of social entrepreneurship, occurs where social value creation is related to a specific community context (PIERRE et al., 2014; RATTEN and WELPE, 2011).

The entrepreneurship process of CEs can be characterized as a re-combination of local resources and activities with the aim of creating social wealth within the community (HAUGH, 2007; PEREDO and CHRISMAN, 2006). Social wealth creation may be motivated by the community's need for endogenous growth, but is also sought as a means of improving a community's reputation and engendering a new sense of pride within economically and socially deprived localities (JOHANNISSON, 1990; JOHNSTONE and LIONAIS, 2004). Within the community entrepreneurship literature, the community is not merely the context but a key participant in the initiation and development of the nascent $\mathrm{CE}$, acting corporately as both entrepreneur and enterprise in pursuit of the common good (DASKALAKI et al., 2015; PEREDO and CHRISMAN, 2006; RATTEN and WELPE, 2011). Rural communities, particularly those in

remote and peripheral regions without realistic prospect of exogenous growth, have frequently responded by initiating community-based ventures to alleviate the worst effects of economic 
distress and empower marginalized communities (MARKUSEN, 2010; KALANTARIDIS and BIKA, 2011).

To distinguish community entrepreneurship from commercial entrepreneurship, this study focuses on the creation of non-profit CEs, where economic surplus is reinvested to increase social value creation rather than distributed to shareholders (AUSTIN et al., 2006; SHAW and CARTER, 2007). As non-profit organizations, the economic value created by CEs is often insufficient to pay for the resources they use, hence there is often a reliance upon non-economic exchange and reciprocity between actors (DEES, 2001).

Because of the resource constraints and limited capacity particularly evident within remote rural locations, rural CEs require the engagement of a large number of stakeholders within the community to access or acquire trading resources (JOHANNISSON, 1990; HAUGH, 2007). CEs typically require a lead actor to assume the role of change agent, developing new activities and building new organizational structures (SHAW and CARTER, 2007). An important aspect of the lead actor's role is to mobilize support for the new venture, and gain access to the necessary financial, physical, human, and other, less tangible, resources required for the new venture's creation (ZOTT and HUY, 2007). While some entrepreneurs build upon existing resources and activities, this study looks at entrepreneurs who introduce radical ideas requiring new resources into the rural community (ZAHRA et al., 2009; DI DOMENICO et al., 2010). These community entrepreneurs are likely to face particular challenges in accessing resources, because the entrepreneurs lack the legitimacy required to introduce novel activities. As a consequence, gaining legitimacy becomes critical to the process of resource acquisition for the emerging CE. 


\section{Legitimacy Building Strategies}

Legitimacy, one of the most important concepts of institutional theory, refers to "a generalized perception or assumption that the actions of an entity are desirable, proper or appropriate within some socially constructed system of norms, beliefs, and definitions" (SUCHMAN, 1995 574). One of the greatest challenges for nascent ventures and entrepreneurs is that they lack the legitimacy needed to convince resource holders to back their ventures. Thus, new ventures need to actively search for legitimacy to be perceived as appropriate organizations by resource providers (KIBLER et al., 2014; ZIMMERMAN and ZEITZ, 2002; ÜBERBACHER, 2014; LOUNSBURY and GLYNN, 2001).

The legitimacy concept explains how organisational actors are constrained, developed, and permitted by regulative, normative and cognitive forces within their environment (ZIMMERMAN and ZEITZ, 2002). Regulative legitimacy concerns how the new venture works and develops according to rules, regulations, and expectations created by powerful actors in the environment, such as the government. Second, normative legitimacy involves how the new venture addresses the norms and values in the environment. Finally, new ventures build cognitive legitimacy when they address collectively accepted practices, knowledge, and ideas. The collective sum of these regulative, normative and cognitive forces can be described as preexisting rules (regulative), norms (normative), and practices (cognitive) that an entrepreneur must navigate in order to achieve the necessary legitimacy to access resources and support for the new venture.

How CEs go about establishing the legitimacy needed to create new activities is little understood. The challenge of establishing legitimacy is especially prominent in rural areas - often characterized by a limited resource base, capacity constraints and conservative attitudes. Entrepreneurs introducing novel and radical ideas may face particular challenges in gaining 
legitimacy in the local community, especially if the ideas are not in line with pre-existing rules, norms, and practices. Because of resource constraints within rural areas, successful new ventures may require resources to be secured from providers external to the rural community. Hence, entrepreneurs may need to build legitimacy both within the rural area and within external environments, where different environments consist of different, competing logics. Hence, CEs operate in a multifaceted environment where the characteristics seen as appropriate by some stakeholders in one environment may be different from what is perceived as appropriate by other stakeholders in another environment. Exploring the context of CEs emergence may add to the literature of legitimacy building, as it offers an example of competing logics. The multiple and competing demands that exist within different environments require the organization to respond accordingly (THORNTON et al., 2012). How do CEs progress from starting in a situation with competing institutional logics (i.e. the introduction of a novel and radical idea into a conservative rural community) to become a legitimate actor attuned to the regulatory, normative and cognitive forces present within different environments?

The institutional entrepreneurship literature has started to explore how competing logics can coexist alongside each other (TRACEY et al., 2011). However, resource-holders are generally described as uniform, and how new ventures appear legitimate to resource holders in different contexts and environments with potentially conflicting demands is not well understood (ÜBERBACHER, 2014). Our focus is not on the different types or dimensions of legitimacy, but rather on the process of legitimation and how legitimacy is developed in an interplay between different stakeholders and within different environments. The paucity of research related to legitimacy building in multifaceted environments such as the creation of CEs warrants an inductive approach. 


\section{METHODOLOGY}

A qualitative case study methodology was used to explore how CEs within two different remote rural communities in Norway gained legitimacy. The case studies offered rich context related information about the communities (FLYVBJERG, 2006; JOHNS, 2006) and made it possible to collect data at different stages and levels in the process (EISENHARDT, 1989). A longitudinal approach was warranted to capture changes over time and reduce problems of retrospective bias (PETTIGREW, 1990; MILLER et al., 1997). Both CEs in our study emerged within rural communities with a sparse population facing challenges from depopulation.

The empirical setting is the numerous cultural festivals that have been established in Norway since the 1980s. Cultural festivals usually take place annually over a week or weekend and, though they vary in size and scope, are most frequently connected to a specific music genre. Although relatively few studies have been undertaken examining the creative sectors in rural areas, the results suggest that sense of place and local rural identity contributes to the production of art and culture (MAYES, 2010; BAYLISS, 2004). Importantly, the role of cultural capital as a major contributor to rural economic performance has been increasingly recognized (TAYLOR, 2013; HUGGINS and CLIFTON, 2011; HUGGINS and THOMPSON, 2015), and there is an emerging interest in both the distinctiveness and potential contribution of the arts and creative sectors in rural areas (BAYLISS, 2004; BELL and JAYNE, 2010). Although there are many examples of for-profit festivals, this study focuses on non-profit festivals, which aim to create new activities and social values within their respective communities. This is a proper context to address the balance between creating something radically new and gaining legitimacy within established contexts. 
The study was conducted over a four years period. Because legitimacy building is particularly important in the earliest stages of venture development (DELMAR and SHANE, 2004), we attempted to gather data covering the initial venture creation period. For both cases we relied on retrospective accounts to map the process prior to and during the initial start-up period of the CEs (MILLER et al., 1997). Data collection in the first CE case started one year after its inception and we followed this case for four years. The second case was chosen to replicate the findings from the first case (YIN, 2003). We therefore selected a case that had been operating for four years to map its historical development retrospectively and follow the development over one year. Data collection ended when there was consensus that the ventures had made a sustained positive contribution to the rural community, indicating that they had built the required legitimacy. We looked for similarities between the two cases related to the strategies used to build legitimacy. Relying on more than one case provided more robust and powerful results and conclusions (Yin, 2003).

Data were collected between 2006 and 2010 using a wide range of sources to facilitate data triangulation. Triangulation provided rich data about the context, process, and activities of the actors involved. Furthermore, using multiple sources reduced the risk of misinterpretation. Primary data were gathered through interviews with the community entrepreneurs and other key actors in the process, as shown in Table 1. The interviews were the main source of data. Narrative interviewing was used to obtain data from the entire entrepreneurial process by asking the interviewees to tell the story from the first time they heard about the emerging CE until the present day. Interviews were undertaken in the informants' home, at their work or at the festival arena. Key actors were interviewed several times and asked to tell the narrative about the activities since the previous interview. The interviewees' stories might have been influenced by the limitations of their memories and the issues the interviewees wanted to share (JONES et al., 
2008). Hence, different actors engaged in the process were interviewed to decreased the risk of retrospective interpretation (EISENHARDT and GRAEBNER, 2007) and obtain more complete information about the process. A total of 28 interviews were conducted with nine different people from each festival. The interviews lasted from half an hour to three hours. An interview protocol with questions about the resource acquisition process was used to solicit information the interviewees did not explain in their narratives.

\section{INSERT TABLE 1 ABOUT HERE}

Participant observations from both festivals supplement the data. In the first case, one of the researchers was an observer during the five-day festival event. The following year the researcher participated as a voluntary staff member and in the third year as an observer at the festival. In the second case, the researcher participated as a voluntary staff member during the two-day festival event. The observations were open ended to achieve the greatest understanding of the festivals; however, the researcher focused on acquiring information about which resources and actors were involved in the festival and why. At the end of each day the researcher made notes about the observations. Being in the field allowed the researcher to develop personal contacts which made it easier to gain trust among the interviewees and discover new informants. Observations and narrative interviewing made it possible to collect data close to real time and to gain a thorough understanding of the process. Secondary data were collected by reviewing e-mail communication, web pages, newspapers and other written documents.

The collected data provided narrative accounts of the process (PENTLAND, 1999) and factual descriptions of context, actors, and events from a large number of sources. Interviews were recorded and transcribed as part of the data analysis process. Interview transcripts and other 
material were read and reread as data were collected, and emerging themes refined and checked through repeat interviews with the main players (YIN, 2003). The views of the different respondents within each case were also compared. Observations and secondary data were primarily used to supplement and validate the data collected from the interviews. Using multiple informants and narrative interviewing in combination with participant observation and historical documentation helped to reduce problems of hindsight bias and memory decay and improved the validity of retrospective reports (MILLER et al., 1997).

To analyze the process we wrote narratives of the resource acquisition process in each case and searched for structures in the narratives (PENTLAND, 1999). Legitimacy emerged from the data as crucially important in the acquisition of resources. The data were categorized to identify the specific strategies used to obtain legitimacy and the categories then compared with the legitimacy literature. The categorization of events into specific strategies, undertaken independently by two researchers, attained a high degree of consensus. The conclusions were reached in a discussion between all authors and as a validity check some of the festival founders read the manuscript and confirmed the findings.

\section{THE CE CASES}

\section{The Groove Valley (TGV)}

The Groove Valley (TGV) case is based within Beiarn, a small community of about 1100 inhabitants, remotely located about two hours drive from the nearest town (Bodø) in Northern Norway. As with many other rural communities, the major challenge is depopulation; the 
population density of Beiarn is $0.9 / \mathrm{km}^{2}$ or $2.4 / \mathrm{sq}$. mile and the current population is less than half its size in the 1960s. The idea of creating a music festival emerged from the municipality as a mechanism to strengthen the community's cultural life and increase its attractiveness to the younger generation.

Since its inception in 2005, The Groove Valley (TGV) has become an annual jazz music festival which takes place over five days in August. TGV provides a meeting place with workshops and clinics where amateur musicians are instructed by, and have the opportunity to play with, professional musicians. There are also open lectures for festival visitors. During the festival the amateurs and professionals play outdoor concerts, jam sessions in the local pub, and concerts in a concert hall and in an art gallery. In addition, camp activities such as sightseeing, caving, sea rafting, and night fishing in the river are offered.

As a result of $\mathrm{TGV}$, the small community has attracted a great deal of positive attention from both regional and national media. For example, one national newspaper had a two-page article with the headline "The Jazz Camp in Beiarn: Jazz Success in a Green Valley" (ASPEN, 2008). This attention has resulted in a more positive perception of the community among the inhabitants and beyond. According to the Mayor: "I think that what has happened, in particular the positive media attention locally, in national newspapers and elsewhere, has made [TGV] something which contributes to strengthening the identity for all of us who come from this community. Yes, it contributes to building our identity in a positive way" (G1 - see Table 1). TGV has led to the establishment of new year-round cultural activities within the community, such as local jazz groups, more regular concerts around the year and a higher level of activity in the municipal music school involving more experienced and educated instructors. TGV has also had an effect on businesses such as the shops, the pub, the local art gallery and the landowners of the fishing river, all of which generate income from the new visitors and activities. Population 
decline in Beiarn is markedly lower for the five years since the festival started compared with the five year period prior to the festival's inception (Table 2), although any direct correlation between net migration patterns and the presence of TGV would be speculative.

\section{The Skiippagurra Festival (SKI)}

Skiippagurra village in the Finnmark region attracted national opprobrium in the 1990s following media reports of prostitution in the local camp ground and, several years after the problem had ceased, still struggled to change its reputation. The Skiippagurra village (population of 250) lies within the remote community of Tana situated close to the Russian border in the North-East of Norway. Tana has a total population of about 3000 mainly Sami inhabitants, a population density of $1 / \mathrm{km}^{2}$ or $2.6 /$ sq. mile, and has experienced population decline of $8.2 \%$ over the past ten years. The municipality attempted to improve the identity of the community and one of their ideas was to establish a music festival for the community's young people.

The Skiippagurra Festival (SKI) is a two-day rock festival which takes place over a weekend in July and has been held annually since 2003. At the festival, international and national rock artists and groups perform outdoor concerts on a river beach. Baltic music is pervasive at the festival, and Sami music and traditions play a key role. The festival provides instructional courses for children to learn the chanting songs of the Sami people, and young people are instructed by professional musicians in concert performance. In addition, SKI also offers outdoor recreational activities, such as sandcastle competitions, volleyball and horse riding.

The festival has successfully changed the media focus on Skiippagurra village both regionally and nationally. The first festival leader reported that: "The first year [National Television] was here ... the story was broadcast on the nine o'clock news, really in prime time, 
and with the right focus" (E3). The importance of SKI was further described: "There is agreement across party lines that the festival is important for the Tana community. ... The Mayor gave a speech in Oslo about changing a negative reputation. The festival is also contributing by making young people proud of being from Tana." (E3). In addition, SKI has had a positive effect on local business life by attracting visitors and tourists, as explained by the festival leader: "[2007] is the first year we had a proper level of sponsorship in terms of cash. Since 2005 we have noticed that local businesses make money from [SKI] and want to become involved." (M3). Tana has also seen a significant reduction in outward migration in the five years since the festival started compared to the five years before (Table 2). However, as with Beiarn, it is impossible to demonstrate any direct causal relationship between population retention and the presence of the SKI festival. Key characteristics of the communities and festivals are shown in Table 2.

\section{INSERT TABLE 2 ABOUT HERE}

\section{FINDINGS: STRATEGIES FOR GAINING LEGITIMACY}

In both cases, the entrepreneurs leading the CEs introduced a new and innovative idea for the community and had high ambitions for their festivals. Hence, both CEs introduced ideas that were far from legitimate within their respective communities. Moreover, both entrepreneurs were from outside their respective communities and lacked the necessary legitimacy within their rural communities to introduce new activities. For instance, the TGV entrepreneur struggled to convince the local inhabitants: "[CX] presented this many times, but his idea was so airy that people shook their heads. They perceived this as impossible to accomplish" (M2). Even people from outside the community expressed scepticism when they heard about the plans: "I thought 
'you will struggle, you sure will'. I was not overly optimistic. However, [CX] had accomplished things before, so it would not be totally surprising if he were able to make a Jazz festival" (M5). Also SKI met opposition to the festival: "There was a lot of opposition when we started - when it became known that we were going to use Skiippagurra ... Many eminent members of the community said: 'Leave us alone', 'Give us exemption from this', 'Couldn't it be another name?'" (CY).

This finding is consistent with earlier research indicating that newcomer entrepreneurs may be in a good position to act as agents of change in rural communities since they identify opportunities related to their external linkages and bring their existing network to the rural communities (TAYLOR, 2013; AKGÜN et al., 2011). However, a particular challenge of newcomers in remote rural areas may be that they are perceived as being ill-attuned to the preexisting rules, norms and practices of the local community, and this lack of legitimacy may result in a limited impact on local entrepreneurship and job creation (KALANTARIDIS, 2010).

Starting the new CEs required a range of resources and, because of the limited resources within the rural communities, the entrepreneurs were dependent on the involvement of a large part of the community. The festivals were non-profits and had limited financial capital to buy other resources. Thus, legitimatizing the venture idea became crucially important to access resources they could not otherwise afford. The importance of building legitimacy in the local community was clearly expressed by the Mayor two years after the TGV festival started: “When I look around in Beiarn, I see that a growing number of the regular inhabitants have opened their eyes for [TGV]. They have got nice concert experiences and feel that this is important for Beiarn as a community. We are totally dependent on this support. If we shall use this much municipal resources, what we do has to be legitimate. I feel that this support and the legitimacy [of TGV] have become stronger" (G1). 
Although the legitimation process involved a range of different prospective resource providers, two main categories of subjects or audiences with distinct rules, norms, and practices appeared; the rural community and the cultural festival linked to an external, professional environment. The identification of two distinct environments, the internal (rural community) environment and the external (cultural festival) environment posed particular challenges for the entrepreneurs, as they needed to be attuned to the pre-existing rules, norms and practices within each environment. Our cases illustrate the need to create legitimacy for the festival as an appropriate activity within the rural community, as well as among stakeholders outside the rural community, in order to acquire the resources necessary to launch and develop the ventures. The festivals needed many volunteers within the local community to work as guards, sell tickets and food, take care of the artists, build the stage scenery and tidy up during and after the festival. They also needed legitimacy among businesses in the community to arrange accommodation, food and nature experiences below the usual market price. Moreover, the CEs needed to be perceived as 'proper' in order to access financial support from the local government and local firms. In addition to the resources required from the internal (rural community) environment, they also needed to receive resources (e.g., artists, sponsorship, technicians and visitors) from the external (cultural festival) environment. Thus, both festivals required legitimacy as a proper music festival within the music industry, among regional and national sponsors and others to receive resources below the market price. However, building legitimacy was a challenging process because the rules, norms, and practices were different in the two environments.

We found that the strategies for building legitimacy differed depending on whether the CE sought legitimacy within the rural community or from the external environment as a music festival. As illustrated in Figure 1, we identified three strategies for building legitimacy for new CEs: conforming to the internal (rural community) environment; conforming to the external 
(cultural festival) environment; and changing the internal (rural community) environment. These strategies appeared partly sequential, because the CEs initially had to conform to the internal and the external environment to obtain initial support and resources. Subsequently, they relied on strategies to change the internal rural community environment in order to introduce new, partly unfamiliar, activities into the rural community. In the following sections we present the three strategies for gaining legitimacy and explore their contribution to the creation of new CEs in rural communities. We discuss the use of each strategy and present an overview and additional examples of the strategies in Table 3.

INSERT FIGURE 1 ABOUT HERE

\section{INSERT TABLE 3 ABOUT HERE}

\section{Strategy 1: Conforming to the Internal Environment}

Conforming to the internal (rural community) environment is a means of minimising opposition and following the tacit rules of the local community, or in the words of Zimmerman and Zeitz (2002): "a new venture that conforms does not question, change, or violate the social structure". In our cases, the internal conforming strategy was evident when the CEs used legitimacy held by other actors in the rural community and when they conformed to the rules, norms and practices of the resource providers within the rural community. For example, the entrepreneurs of both CEs were from outside the community and urged the local municipality to become the owner and financially responsible party of the CE. This was explained by a government leader in the TGV municipality: "[CX] tried to get his colleagues [in the local government] interested ... He 
repeatedly tried [to get me involved] because I had the money” (M2). Being part of the Municipality was also seen as crucial for the SKI festival, as explained by the first festival leader: "To be Municipal actually means that we have the Municipal treasury as security. We can afford to take a loss.” (M2). By being officially connected to the local government, the festivals immediately attained a level of legitimacy within the community since community members assumed that the venture would act according to local bureaucratic decision making processes and the goal of rural development.

SKI had difficulties gaining access to resources in the local community due to opposition from the village which had been experiencing some social problems. In response, the entrepreneur included individuals from the village in creating ownership for the idea: "We were very aware. In the first press release there was a picture of a girl [...], she was from Skiippagurra. We were very interested in including young people from that village" (M2). The headmaster of the municipal culture school for children was invited to join the CE: "It was accepted that he became the festival leader, because he had a respected name” (CY). In addition, a young woman from the Skiippagurra village became the festival's press spokesperson: "I was included because I was from Skiippagurra. I think I was an alibi!" (V1). In addition, the owner of the local festival arena also became involved in the organization. Through the deliberate strategy of involving local community members, the CE established its willingness to conform to local norms and practices. This finding is consistent with earlier research that new ventures can build legitimacy through employing individuals or developing networks to actors that already have obtained legitimacy (RAO et al., 2008).

Both CEs were innovative and initially faced scepticism and low participation levels from the rural community. Introducing a completely new idea appeared to be too radical without connecting it to something familiar within the community. For example, TGV hosted an 
internationally known jazz musician one year; however, he did not attract the audience as they had not heard of him: "It was not Mike Stern who attracted people [last year], it was the local boys, The Young Ones, who played with him and joined the jam" (V4). As a result, the entrepreneurs had to combine their innovative ideas with more familiar community traditions and conform to the demands of potential resource providers in the local community. The entrepreneur of TGV combined his innovative jazz music idea with a sports base camp activity for youths that already existed in the community and the outdoor opening concert was created around a traditional coffee meeting in the community to lower the barriers for the community inhabitants to attend. In addition, the local government convinced the entrepreneur to include artists more familiar to a broader audience at the festival to engage a larger part of the community. SKI also offered nature based and sports activities which built upon existing activities in the community as well as including Sami music and traditions. These adaptations to suit the local environment were fundamental in gaining legitimacy for the CE. Thus, a key conclusion is that emerging CEs are more likely to gain legitimacy among resource providers in the rural community if they conform to established rules, norms, and practises in the internal community environment initially in the start-up process (SUCHMAN, 1995).

\section{Strategy 2: Conforming to the External Environment}

The strategy of conforming to the external (cultural festivals) environment was evident when the CEs used legitimacy that belonged to other individuals or organizations in the external environment and when the CEs conformed to demands from external resource providers. As an example, TGV recruited a respected and successful jazz musician (M1) living in the regional centre to the festival organizing committee. This helped the entrepreneur gain access to other 
known artists, as explained by the musician: "When [CX] started the festival, he started from scratch. He asked me if I could pull strings to attract such and such [people] and about support and so on. I think he needed somebody who had a certain position in the milieu [...]. When [CX] applies [for economic support] he uses me for what I am worth, especially in the beginning" (M1). The inclusion of a known jazz musician proved instrumental in legitimizing the festival among international jazz musicians and resource providers. Notably, there was an expectation that the $\mathrm{CE}$ would conform to the expectations and standards of the music industry demanded by this jazz artist in return for support given.

SKI relied on networks and connections with external organizations to enhance their legitimacy. Due to the history of negative publicity about the community, SKI struggled to be perceived as a proper festival, as explained by the entrepreneur who tried to book artists: "When you present yourself, call for first time or send an e-mail; 'Hi, this is [CY] who works for SKI'. Many times I had to call back. I heard them say: 'it's the one from SKI, should we send a band to Skiippagurra?' The worst of it was that I became embarrassed myself ... The next year in 2005 in the spring we got economic support from the Norwegian Culture Council ... After that we got many telephone calls from artist managers who called to congratulate us and asked if we were ready to book from them" (CY). SKI's legitimacy in the music industry increased significantly when they became associated with the Norwegian Culture Council, already regarded as a prestigious, resource-rich and legitimate actor within the industry. Similarly, the entrepreneur in TGV utilised positive feedback from the regional Jazz Centre (S1) to establish legitimacy in the external environment: "We refer to the Jazz Centre when we present the project for potential collaboration partners, otherwise it will be impossible to show our seriousness in the work" (CX-email). 
Hence, it became clear that both festivals were shaped according to demands in the external environment. SKI was conscious of showcasing Sami culture at the festival in order to receive support from the Sami Council, as explained by one of the team members: "It is important in order to get support from Sami Council - we are very conscious about promoting our own culture, that we promote the Sami culture” (M2). TGV also had to include public concerts during one day of the festival to be eligible for support from the Norwegian Culture Council. Thus, a key conclusion for this discussion is that emerging CEs are more likely to gain legitimacy among external resource providers if they conform to established rules, norms, and practices in the external environment initially in the start-up process.

\section{Strategy 3: Changing the Internal Environment}

The entrepreneurs of both CEs had high musical ambitions for the festivals, and the local communities were unfamiliar with some of the rules, norms, and practices of the new venture. For instance, the main goal of the local community was to contribute to rural development by developing a better reputation and promote local businesses. In contrast, the goal of external resource holders was to meet and develop good music experiences with other professional musicians.

When developing new products, services and/or practices that do not conformwith existing rules, norms and practices, it has been suggested that legitimacy can be built by manipulating the environment (ZIMMERMAN and ZEITZ, 2002; SUCHMAN, 1995). Here, manipulation refers to a substantial departure from prior practice (ZIMMERMAN and ZEITZ, 2002), and applying such strategies are challenging for the nascent CEs that lack power and

resources. Rather than manipulating or developing new rules, norms and practices, the 
entrepreneurs tried to change the local community to accept the requirements of the external environment.

To legitimatize the quality of the music element of the festival, the TGV entrepreneur sent the positive e-mail he had received from the regional Jazz centre (S1) to organizations in the rural community which stated: "The jazz camp will be created in a close collaboration with the [Jazz Centre]. They have the right contacts." Even the fact that TGV was selected as a case in this research study was used to actively manipulate the rural community to believe in the idea. According to the entrepreneur, supporting the festival was worthwhile because it had attracted attention among academics outside the community. In several interviews in the local newspaper, the entrepreneur emphasized the ongoing research on the festival. The SKI entrepreneur used the legitimacy gained by conforming to the demands of the Norwegian Culture Council to challenge the internal environment: "I have argued much in the board and among key people [...] If we ask that band to come, the other band will not be here, and then the Norwegian Culture Council will not give us money" (CY). This shows how the CEs built on legitimacy gained in the external environment in order to change the internal environment.

The CEs also worked with the media to gain trust in the local community. For TGV, extensive media coverage helped to improve the legitimacy of the festival: "That we have got good media coverage has given us goodwill among the politicians related to the economy. [...]. One of the politicians said that this wasn't the type he liked, the music and everything, but he understood that this was good" (M2). Local businesses also saw the benefits created by the publicity of TGV in regional and national media and increased sponsorship donations each year. The attitude towards the $\mathrm{CE}$ in the Skiippagurra village became more positive when the inhabitants saw the new and more optimistic view of the Skippagurra name in the media. 
Thus, a key conclusion is that when introducing a new practice to a rural community, emerging CEs are more likely to gain legitimacy among resource holders in the rural community if they use strategies that challenge and change the rules, norms, and practices in the internal community environment. Changing the environment was more complicated and took longer than conforming to the environment. Moreover, it seems that emerging CEs are more able to change the internal community environment when they have already obtained an initial level of legitimacy by conforming to both internal and external rules, norms and practices. We observed that the strategy of changing the internal environment to build legitimacy for the $\mathrm{CE}$ was achieved partly by using legitimacy acquired from conforming to the external environment. Thus, different environments with different norms can be used purposefully to build legitimacy.

\section{CONCLUSIONS AND IMPLICATIONS}

This paper explored the process of establishing music festivals which led to new cultural activities in two remote rural communities. Our study integrates institutional theory with the community entrepreneurship literature to theorize on how emerging CEs are able to construct new practises in their communities. We show that different and partly conflicting institutional contexts shaped both the opportunities and how these were exploited to create a CE. Hence, community entrepreneurship is an iterative process that both shapes and is shaped by the institutional environment. The entrepreneurs deliberately built CEs by using different strategies to interact with different institutional environments.

In particular, we studied how nascent CEs in rural areas are able to build the legitimacy necessary to access resources required for their development. We identified three legitimacy building strategies for CEs: conforming to the internal (rural community) environment; 
conforming to the external (cultural festival) environment; and changing the internal (rural community) environment. When conforming to the environment, the CEs adapted to existing rules, norms and practices in order to gain legitimacy. We propose that in order to gain initial legitimacy in the start-up process, emerging CEs need to conform to established practises both in the internal rural community environment and in the external environment. Moreover, strategies to challenge and change the internal community environment are crucial for CEs aiming to introduce new practices within rural communities. However, strategies of change are more likely to succeed when the CEs already have obtained an initial level of legitimacy by conforming to both internal and external rules, norms and practises. The interplay between the three legitimacy building strategies over time is illustrated in Figure 1.

Because the emerging CEs are non-profit and the exchange for most of the resources is non-monetary, legitimacy seems to be especially important for the development of CEs compared to other new ventures. The involvement of local residents in a rural or local community has been highlighted in earlier studies of CEs (HAUGH, 2007; PEREDO and CHRISMAN, 2006), as well as in studies that have considered broader aspects of rural community development (BAYLISS, 2004; HAUGHTON, 1998). Our study extends the extant literature by showing that CEs do not emerge in isolation from the rural community, and the need for resources from stakeholders in the external environment as well. This implies that future studies on community entrepreneurship in rural environments should distinguish between the internal and the external environment because they offer distinct resources and respond to different types of legitimacy. By using a longitudinal approach, this study showed the dynamics of the legitimacy building process. Early in the start-up process emerging ventures need to build legitimacy through conformance to preexisting rules, norms and practices before they are able to change the environment. External and internal legitimacy is built in an iterative process, making it possible for the venture to leverage 
external legitimacy into internal legitimacy. In other words, rural community members will be more confident in supporting the venture if they perceive the venture to be credible among external stakeholders.

This study shows how the inclusion of new individuals in the CE organization is used as a strategy to create legitimacy for the nascent venture. This strategy leads to increased legitimacy, but imposes changes on the enterprises as each new individual is likely to have personal goals and ideas for the $\mathrm{CE}$ that need to be taken into consideration through a process of reciprocity. Hence, the more individuals from the community are involved, the more the CE becomes embedded within the community.. This study extends prior literature (KIBLER et al., 2014; MAIR and MARTÍ, 2006; PEREDO and CHRISMAN, 2006) by showing how strategies of gaining legitimacy are a driving-force for embedding the CEs in the structures of the local rural community.

The cases in our study are situated in a national context with a well-developed welfare system and a strong public sector. The results might also be relevant in other contexts where the public sector is not as well developed, but where other actors play influential roles (TAYLOR, 2013; HEINZE et al., 2016; HAUGHTON, 1998). To create more robust results, more cases of legitimacy building from different contexts are needed.

Our two music festival cases clearly show how CEs can create positive publicity and improve public perceptions and reputation of a rural community, and potentially contribute to the restructuring of rural areas into commodities. The cases also illustrate how entrepreneurs in the creative industries successfully launch new initiatives in rural areas, which can inform practice and policy about the scarcely studied rural cultural economy (BELL and JAYNE, 2010). Our study suggests that public policies for the development of CEs should take into account the need for legitimacy both within the rural community and among external actors, and the reciprocal 
nature of legitimacy building. This advice may also be relevant for policies related to the development of a broader range of activities in rural communities, such as social or cultural enterprises (TAYLOR, 2013; MARKUSEN, 2010).

To conclude, our study extends the literature on legitimacy building in the context of different audiences with competing logics. While most studies assume that legitimacy is developed similarly across different audiences (ÜBERBACHER, 2014), our study shows that legitimacy built in one audience can be strategically used to develop legitimacy across other audiences. Hence, we show how legitimacy can be developed differently across different audiences and how legitimacy is built in an iterative process over time.

\section{REFERENCES}

DELAMERE T. A. (2001) Development of a scale to measure resident attitudes toward the social impacts of community festivals, part II: Verification of the scale, Event Management 7, 25-38.

GURSOY D., KIM K. and UYSAL M. (2004) Perceived impacts of festivals and special events by organizers: an extension and validation, Tourism Management 25, 171-81.

TAYLOR C. (2013) Between Culture, Policy and Industry: Modalities of Intermediation in the Creative Economy, Regional Studies, 1-12.

MAYES R. (2010) Doing cultural work: Local postcard production and place identity in a rural shire, Journal of Rural Studies 26, 1-11.

ANDRES L. and CHAPAIN C. (2013) The Integration of Cultural and Creative Industries into Local and Regional Development Strategies in Birmingham and Marseille: Towards an Inclusive and Collaborative Governance?, Regional Studies 47, 161-82.

BOYLE M. (1997) Civic boosterism in the politics of local economic development ? 'institutional positions' and 'strategic orientations' in the consumption of hallmark events, Environment and Planning A 29, 1975-97.

MARKUSEN A. (2010) Organizational complexity in the regional cultural economy, Regional Studies 44, 813-28.

KIBLER E., KAUTONEN T. and FINK M. (2014) Regional Social Legitimacy of Entrepreneurship: Implications for Entrepreneurial Intention and Start-up Behaviour, Regional Studies 48, 995-1015.

BITEKTINE A. and HAACK P. (2015) The "Macro" and the "Micro" of Legitimacy: Toward a Multilevel Theory of the Legitimacy Process, Academy of Management Review 40, 49-75.

CASTELLÓ I., ETTER M. and ÅRUP NIELSEN F. (2015) Strategies of Legitimacy Through Social Media: The Networked Strategy, Journal of Management Studies, n/a-n/a.

JOHANNISSON B. (1990) Community entrepreneurship -cases and conceptualization, Entrepreneurship \& Regional Development 2, 71-88.

JOHNSTONE H. and LIONAIS D. (2004) Depleted communities and community business entrepreneurship: revaluing space through place, Entrepreneurship \& Regional Development 16, 217 - 33.

HAUGH H. M. and PARDY W. (1999) Community entrepreneurship in north east Scotland, International Journal of Entrepreneurial Behaviour \& Research 5, 163-72. 
BORCH O. J., FØRDE A., RØNNING L., VESTRUM I. K. and ALSOS G. A. (2008) Resource configuration and creative practices of community entrepreneurs, Journal of Enterprising Communities: People and Places in the Global Economy 2, 100-23.

HEINZE K. L., BANASZAK-HOLL J. and BABIAK K. (2016) Social Entrepreneurship in Communities, Nonprofit Management and Leadership, n/a-n/a.

LOTZ J. (1989) Community Entrepreneurs, Community Development Journal 24, 62-6.

MAIR J. and MARTÍ I. (2006) Social entrepreneurship research: A source of explanation, prediction, and delight, Journal of World Business 41, 36-44.

PEREDO A. M. and MCLEAN M. (2006) Social entrepreneurship: A critical review of the concept, Journal of World Business 41, 56-65.

DASKALAKI M., HJORTH D. and MAIR J. (2015) Are Entrepreneurship, Communities, and Social Transformation Related?, Journal of Management Inquiry 24, 419-23.

ALSOS G. A., CARTER S., LJUNGGREN E. and WELTER F. (2011) The Handbook of research on entrepreneurship in agriculture and rural development. Edward Elgar, Cheltenham.

BEAUDOIN J.-M., LEBEL L. and BOUTHILLIER L. (2011) Agricultural and forestry entrepreneurship: learning from the experience of an Aboriginal community in Canada, in ALSOS G., CARTER S., LJUNGGREN E. and WELTER F. (Eds) The Handbook of Research on Entrepreneurship in Agriculture and Rural Development, pp. 28195. Edward Elgar, Cheltenham.

ZIMMERMAN M. A. and ZEITZ G. J. (2002) Beyond survival: Achieving new venture growth by building legitimacy, Academy of Management Review 27, 414-31.

ÜBERBACHER F. (2014) Legitimation of New Ventures: A Review and Research Programme, Journal of Management Studies 51, 667-98.

LOUNSBURY M. and GLYNN M. A. (2001) Cultural entrepreneurship: Stories, legitimacy, and the acquisition of resources, Strategic Management Journal 22, 545-64.

VAN WERVEN R., BOUWMEESTER O. and CORNELISSEN J. P. (2015) The power of arguments: How entrepreneurs convince stakeholders of the legitimate distinctiveness of their ventures, Journal of Business Venturing 30, 616-31.

AUSTIN J., STEVENSON H. and WEI-SKILLERN J. (2006) Social and Commercial Entrepreneurship: Same, Different, or Both?, Entrepreneurship Theory and Practice 30, 1-22.

HAUGH H. (2007) Community-led social venture creation, Entrepreneurship Theory and Practice 31, 161-82.

PEREDO A. M. and CHRISMAN J. J. (2006) Toward a theory of community-based enterprise, Academy of Management Review 31, 309-28.

PIERRE A., VON FRIEDRICHS Y. and WINCENT J. (2014) Entrepreneurship in Society: A Review and Definition of Community-Based Entrepreneurship Research, in LUNDSTRÖM A., ZHOU C., VON FRIEDRICHS Y. and SUNDIN E. (Eds) Social Entrepreneurship, pp. 239-57. Springer International Publishing.

ZAHRA S. A., RAWHOUSER H. N., BHAWE N., NEUBAUM D. O. and HAYTON J. C. (2008) Globalization of social entrepreneurship opportunities, Strategic Entrepreneurship Journal 2, 117-31.

RATTEN V. and WELPE I. M. (2011) Special issue: Community-based, social and societal entrepreneurship, Entrepreneurship \& Regional Development 23, 283-6.

KALANTARIDIS C. and BIKA Z. (2011) Entrepreneurial origin and the configuration of innovation in rural areas: the case of Cumbria, North West England, Environment and Planning A 43, 866-84.

SHAW E. and CARTER S. (2007) Social entrepreneurship: Theoretical antecedents and empirical analysis of entrepreneurial processes and outcomes, Journal of Small Business and Enterprise Development 14, 418-34.

DEES J. G. (2001) The Meaning of "Social Entrepreneurship", p. 5. Stanford University: Draft Report for the Kauffman Center for Entrepreneurial Leadership.

ZOTT C. and HUY Q. N. (2007) How entrepreneurs use symbolic management to acquire resources, Administrative Science Quarterly 52, 70-105.

ZAHRA S. A., GEDAJLOVIC E., NEUBAUM D. O. and SHULMAN J. M. (2009) A typology of social entrepreneurs: Motives, search processes and ethical challenges, Journal of Business Venturing 24, 519-32.

DI DOMENICO M., HAUGH H. and TRACEY P. (2010) Social Bricolage: Theorizing Social Value Creation in Social Enterprises, Entrepreneurship Theory and Practice 34, 681-703.

SUCHMAN M. C. (1995) Managing legitimacy: Strategic and institutional approaches, Academy of Management Review 20, 571.

THORNTON P. H., OCASIO W. and LOUNSBURY M. (2012) The institutional logics perspective : a new approach to culture, structure, and process. Oxford University Press, Oxford. 
TRACEY P., PHILLIPS N. and JARVIS O. (2011) Bridging Institutional Entrepreneurship and the Creation of New Organizational Forms: A Multilevel Model, Organization Science 22, 60-80.

O'NEIL I. and UCBASARAN D. (2011) BUILDING LEGITIMACY IN THE FACE OF COMPETING INSTITUTIONAL LOGICS: EVIDENCE FROM SUSTAINABILITY-DRIVEN ENTREPRENEURS, Frontiers of Entrepreneurship Research 31, Article 4.

FLYVBJERG B. (2006) Five Misunderstandings About Case-Study Research, Qualitative Inquiry 12, 219-45.

JOHNS G. (2006) The essential impact of context on organizational behavior, Academy of Management Review 31, 386-408.

EISENHARDT K. M. (1989) Building Theories from Case-Study Research, Academy of Management Review 14, 532-50.

PETTIGREW A. (1990) Longitudinal field research on change: theory and practice, Organization Science 1, 267-92. MILLER C. C., CARDINAL L. B. and GLICK W. H. (1997) Retrospective Reports in Organizational Research: A Reexamination of Recent Evidence, The Academy of Management Journal 40, 189-204.

BAYLISS D. (2004) Ireland's creative development: local authority strategies for culture-led development, Regional Studies 38, 817-31.

HUGGINS R. and CLIFTON N. (2011) Competitiveness, creativity, and place-based development, Environment and Planning A 43, 1341-62.

HUGGINS R. and THOMPSON P. (2015) Culture and Place-Based Development: A Socio-Economic Analysis, Regional Studies 49, 130-59.

BELL D. and JAYNE M. (2010) The creative countryside: Policy and practice in the UK rural cultural economy, Journal of Rural Studies 26, 209-18.

DELMAR F. and SHANE S. (2004) Legitimating first: organizing activities and the survival of new ventures, Journal of Business Venturing 19, 385-410.

YIN R. K. (2003) Case study research: design and methods. Sage, Thousand Oaks, California.

JONES R., LATHAM J. and BETTA M. (2008) Narrative construction of the social entrepreneurial identity, International Journal of Entrepreneurial Behaviour \& Research 14, 330-45.

EISENHARDT K. M. and GRAEBNER M. E. (2007) Theory building from cases: Opportunities and challenges, Academy of Management Journal 50, 25-32.

PENTLAND B. T. (1999) Building process theory with narrative: From description to explanation, Academy of Management Review 24, 711-24.

ASPEN J. G. (2008) Jazz-campen i Beiarn - jazz-suksess i grøn bygd, Nationen .

AKGÜN A. Y. A., BAYCAN-LEVENT T. N., NIJKAMP P. and POOT J. (2011) Roles of local and newcomer entrepreneurs in rural development: A comparative meta-analytic study, Regional Studies 45, 1207-23.

KALANTARIDIS C. (2010) In-migration, entrepreneurship and rural-urban interdependencies: The case of East Cleveland, North East England, Journal of Rural Studies 26, 418-27.

RAO R. S., CHANDY R. K. and PRABHU J. C. (2008) The fruits of legitimacy: Why some new ventures gain more from innovation than others, Journal of Marketing 72, 58-75.

HAUGHTON G. (1998) Principles and practice of community economic development, Regional Studies 32, 872-7. 